\title{
Animal domestication in the era of ancient genomics
}

Laurent A. F. Frantz ${ }^{1 \dagger}$, Daniel G. Bradley ${ }^{2}$, Greger Larson $^{3}$ and Ludovic Orlando ${ }^{4,5 \dagger}$

${ }^{1}$ School of Biological and Chemical Sciences, Queen Mary University of London, London, UK.

${ }^{2}$ Smurfit Institute of Genetics, Trinity College Dublin, Dublin, Ireland

${ }^{3}$ The Palaeogenomics \& Bio-Archaeology Research Network, Research Laboratory for Archaeology and History of Art, The University of Oxford, Oxford, UK.

${ }^{4}$ Laboratoire d'Anthropobiologie Moléculaire et d'Imagerie de Synthèse, CNRS UMR 5288, Université de Toulouse, Université Paul Sabatier, Toulouse, France

${ }^{5}$ Lundbeck Foundation GeoGenetics Center, University of Copenhagen, Copenhagen, Denmark

$\dagger$ email: Laurent Frantz (ORCID: 0000-0001-8030-3885; laurent.frantz@qmul.ac.uk); Ludovic Orlando (ORCID: 00000003-3936-1850 ; ludovic.orlando@univ-tlse3.fr)

\begin{abstract}
The domestication of animals led to a major shift in human subsistence patterns, [Au: human subsistence patterns OK?] from a hunter-gatherer to a sedentary agricultural lifestyle, which ultimately resulted in the development of complex societies. Over the past 15,000 years, the phenotype and genotype of multiple animal species, such as dogs, pigs, sheep, goats, cattle and horses, have been substantially altered during their adaptation to the human niche. Recent methodological innovations, such as improved ancient DNA extraction methods and next-generation sequencing, have made possible the sequencing of whole ancient genomes and helped researchers to reconstruct the process by which animals entered into domestic relationships with humans and were subjected to novel selection pressures. Here, we discuss and update key concepts in animal domestication in the light of recent contributions from ancient genomics.
\end{abstract}

\section{[H1] Introduction}

Animal domestication was one of the most important transitions in human history ${ }^{1,2}$, beginning with the longterm association between hunter-gatherers and wolves more than 15,000 years ago ${ }^{3}$. Following the emergence of mixed-crop farming societies ${ }^{1,2}$, and between 11,000 and 4,000 years ago (roughly the Neolithic Age [G] through to the Bronze Age [G] ) numerous other species, including but not limited, to sheep, goats, cattle, pigs, chickens and horses, became incorporated within human societies. Since their domestication, animals have occupied a wide range of roles, from simply being tolerated, to being venerated within ritual practices, to providing humans with other benefits, including food, clothing, material for construction, transportation, herding and hunting. The diversification of phenotypes evident in multiple domesticated taxa have also provided generations of biologists with a key model with which to study evolution ${ }^{4,5}$.

The process by which humans voluntarily or involuntarily transformed animals into the diverse resources they now represent has traditionally been documented through two complementary approaches. The first approach, based on the archaeological record, documents morpho-anatomical changes and cultural innovations through space and time ${ }^{6-8}$. Osteological changes ${ }^{9}$, age of death and sex ratio profiles ${ }^{10}$, isotopic signatures ${ }^{11}$ and traces of material culture (for example, harnesses ${ }^{12}$ and corrals ${ }^{13}$ ) represent some of the diverse markers for the shift in the relationship between humans and animals, which we now refer to as indicators of domestication. The archaeological record is fragmentary, 
however, and many traits (such as colouration, docility and fecundity) that probably diverged in domestic animals relative to their wild ancestors in the early stages of domestication, are osteologically invisible.

The second approach makes use of genetic data obtained from modern domestic animals to both retrace their geographic and temporal origins ${ }^{14-18}$ and discover the genetic basis underlying domestic traits ${ }^{19,20}$. For example, geographic patterns of genetic diversity have typically been used to infer the location of initial domestication centres ${ }^{21-}$ ${ }^{23}$. In addition, the substantial phenotypic diversity, both between and within modern domesticated animal populations, combined with powerful techniques that make use of genetic variation at the genome scale, have revealed how specific loci affect traits such as coat colour, size, fat content, circadian clocks and behaviour ${ }^{20}$. Genomic information obtained from living animals, however, only provides a contemporary snapshot of a long-term evolutionary process, and the validity of inferences about the past that are based solely on analyses of modern populations is contentious.

In the past decade, novel molecular techniques have enabled access to genetic information from past populations, offering the opportunity to combine the time-depth of archaeology with the resolution of genetic data. Here, we synthesize how genetic data retrieved from ancient animal remains (Fig. 1) have revolutionized our understanding of the process of animal domestication, from the early stages to the most recent transformations that have resulted from modern breeding practices. One emerging, overarching theme debunks the simplistic view that reproductive control and isolation from wild populations are common features of animal domestication, revealing instead a highly dynamic, non-linear and taxon-specific evolutionary processes (Fig. 2). [Au: Edit OK?]

\section{[H1] Methods in ancient genomics}

The first successful extraction of ancient DNA was carried out in the mid-1980s, with the cloning and sequencing of short mitochondrial-DNA fragments obtained from 19th century museum skin samples of the quagga, a now-extinct zebra species ${ }^{24}$. The polymerase chain reaction (PCR) was instrumental in overcoming the generally limited amount of DNA in ancient remains, and to generate sufficient numbers of DNA copies from pre-selected loci. The amplification process was, however, not without limitations, owing to the poor chemical nature of ancient DNA, introducing recombining artefacts and inflated error rates ${ }^{25}$. With the development of methods for DNA extraction from bones and teeth ${ }^{26}$, a considerably larger archaeological record became amenable to DNA sequencing. Until the advent of next-generation sequencing [G] (NGS), however, the amount of retrievable genetic information was mostly limited to a handful of loci and specimens. With a few exceptions ${ }^{27}$, pre-NGS studies typically leveraged short stretches of mitochondrial DNA to retrace the phylogenetic affinities between past and present species and populations ${ }^{28,29}$. As the ultrashort DNA fragments obtainable from ancient samples are naturally suited to the massively parallel sequencing capacity of $\mathrm{NGS}^{30}$, this technique rapidly led to the characterization of the first nearly-complete ancient genomes $^{31,32}$ (see Fig. 1 for a summary of the resources available for various domesticated animal species).

Four main methodological advances have contributed to the characterization of genome-wide DNA time-series for whole populations ${ }^{33}$. First, ever-improving NGS instruments provided the necessary throughput to enable shotgun sequencing of ancient genomes, even in cases in which the fraction of DNA from environmental microbial contaminants vastly exceeds that of the so-called endogenous DNA [G]. Second, capture techniques [G] have helped focus sequencing efforts on pre-defined sets of targets so that population data can be recovered for only a fraction of the $\operatorname{cost}^{34}$, albeit with the drawbacks that only pre-defined variants are assayed and that the capture step could produce bias

${ }^{35}$. Third, the whole molecular toolkit underlying DNA extraction (such as bleaching and double-digestion ${ }^{36}$ ) and DNA library construction (especially single-stranded DNA methods ${ }^{37,38}$ ) has been fine-tuned to the challenging chemical nature of ancient DNA molecules. Last, these technical developments, such as uracil-DNA glycosylase (UDG) treatment (to remove $\mathrm{C} / \mathrm{G} \rightarrow \mathrm{T} / \mathrm{A}$ misincorporations from ancient DNA molecules) ${ }^{39,40}$, combined with the discovery that 
specific bone elements have generally improved DNA preservation rates, especially the inner ear bone ${ }^{41}$, have considerably enhanced experimental success. Altogether, these methodological advances have provided access to a whole new range of samples with extremely limited preservation that were previously incompatible with DNA analyses (for example, many samples from the Fertile Crescent ${ }^{42-44}$ ).

\section{[H1] Early domestication}

\section{[H2] The geographic and temporal origin of domesticated animals}

An understanding of the early phases of animal domestication has eluded biologists and archeologists for decades. Aside from species that were unequivocally domesticated from geographically restricted wild ancestors (for example, sheep and goats ${ }^{45}$ ) or that originated in well-defined domestication centres such as the Fertile Crescent (for example, pigs ${ }^{46}$ and Bos taurus cattle ${ }^{47,48}$ ), the geographic and temporal origin of other species remain contentious.

For example, progress in pinpointing the origin of dogs has been hampered by the lack of reference data from extinct Pleistocene wild canids, subtle morphological changes between wild and domestic populations during early phases of domestication and the absence of unequivocal material culture accompanying early stages of domestication ${ }^{49,50}$. In the case of horses, substantial morphological changes that differentiate wild and domesticated populations of horses only appear in the early Iron Age ( 3,000 years ago), whereas the earliest evidence of harnessing, milking and corralling can be found in the Botai culture of the Eneolithic period in Central Asia, $\sim 5,500$ years ago ${ }^{13,51}$. A lack of strong phylogeographic structure in horses and several other species has also hindered the power of modern genetics to retrace both the number and location of domestication centres. For example, the reciprocal monophyly of dogs and wolves implies that dogs are not genetically close to any specific wolf population, and that the wild ancestor of dogs is now extinct ${ }^{52,53}$. The latter is also true in horses, where possible centres outside of the traditional domestication centre (the Central Asian steppes), such as Iberia, have been proposed on the basis of a higher genetic diversity in modern breeds ${ }^{54}$. By contrast, highly divergent genomes within cattle ${ }^{55}$ (taurus and zebu) and pigs (European and East Asian) have been interpreted as evidence for the independent domestication of geographically and genetically divergent populations across Eurasia.

Recent genomic evidence from ancient horses (from 4,700-4,000 years ago) has revealed the presence of a now extinct lineage of horses in Iberia, ruling out this population as the ancestor of modern domestic horses ${ }^{56}$. It remains possible that these local horses underwent a domestication process analogous to the archaeologically and genetically attested process in Central Asia that occurred 5,500 years ago, and that this putative domestic population in Iberia was subsequently replaced by another domestic lineage. In fact, population replacement is common in horses. The ancestry of the earliest domestic horses associated with Central Asian cultures of 5,500 years ago ${ }^{57}$ was replaced between 5,000 and 4,000 years ago by the ancestry associated with modern horses ${ }^{56}$. Additional archaeological and genetic evidence is required to test hypotheses related to independent origins of regional populations.

The simultaneous analyses of ancient dog genomes and the archaeological pattern of dog remains suggest that modern dog populations may be derived from independent wolf populations in Western and Eastern Eurasia ${ }^{52}$, although this interpretation has been questioned by some researchers ${ }^{58}$. The situation is much clearer in North America, where ancient genomes have unequivocally demonstrated that native American dogs are the descendants of dogs that were introduced over 10,000 years ago from Siberia ${ }^{59,60}$.

In species such as goats, for which the distribution of their wild ancestors was geographically far more circumscribed, ancient genomes have revealed a complex contribution of multiple, genetically divergent wild lineages to early domestic populations ${ }^{43}$. This pattern could be the result of either continuous incorporation of wild individuals into domestic populations, or independent processes of domestication in different regional settings ${ }^{43}$, with the former 
scenario supported by the fairly frequent incorporation of wild individuals into domestic populations of cattle and pigs 44,61,62 . [Au: Edit OK? or is 'fairly frequent introgression' more correct?] For example, evidence from ancient genomes demonstrates that local wild auroch populations contributed to the genetic make-up of domestic cattle lineages in North Africa, Europe and the British Isles ${ }^{42,63}$. In pigs, the Near Eastern genomic affinity of the first domestic pigs transported into Europe was nearly completely erased by gene flow with the European wild boar ${ }^{44,64}$. The genomic patterns obtained [Au: obtained instead of derived OK?] from ancient dogs and wolves, however, suggest that dogs were almost entirely reproductively isolated from wolves in both Europe ${ }^{52,58}$ and the Americas ${ }^{59}$ for over 10,000 years, although limited gene flow likely occurred in specific lineages, such as arctic dogs ${ }^{65}$.

\section{[H2] Genetic integrity during domestication}

[H3] Reproductive isolation. The prevailing narrative has held that animal domestication required the establishment and maintenance of reproductive isolation between wild and domestic populations (Fig. 2). Recent interpretations of the archaeological record, however, have questioned this assumption ${ }^{66}$, and the recently generated spatiotemporal genomic patterns of pigs $^{44,64}$, horses $^{67}$, cows $^{42}$ and goats ${ }^{43}$ clearly demonstrate that severing gene flow was not necessary to maintain domestic populations. Instead, the ancient genomic record suggests a new narrative for animal domestication in which persistent introgression with wild populations that did not feature in the initial domestication trajectory play a prominent part in the evolution of domestic animal genomic ancestry (Fig. 2).

This new perspective raises puzzling questions as to how domesticated phenotypes can be maintained in the absence of reproductive isolation. A current model based on speciation theory [Au: 'based on' OK?] proposes that only a limited number of loci (termed an 'island of domestication') contribute to phenotypic differentiation between wild and domesticated animal populations ${ }^{68}$. Interestingly, linkage mapping studies in maize have identified a small number of loci that have a substantial effect on the morphological differences between maize and teosinte, suggesting that such a model might also apply to plants ${ }^{69}$. In cases in which a small number of genes explain major differences between wild and domestic populations, selection need only act on these loci to maintain phenotypic integrity, even in the presence of extensive gene flow.

Genomic work in pigs suggests that $M C 1 R$ (encoding melanocortin 1 receptor), the gene that underlies coat colour variation, may represent an island of domestication ${ }^{44}$. Genes involved in neural crest cell [G] (NCC) formation, migration and differentiation have also been proposed to underpin the common suite of biological features known as the 'domestication syndrome'. This syndrome includes various phenotypic traits, such as coat colouration and floppy ears, which appear in many domestic animals, as well as in foxes that were selected for tameness during the Belyaev Fox Farm experiment ${ }^{70}$. Although the robustness of the domestication syndrome and the extent to which the Belyaev Fox Farm experiment could be used as evidence for its existence has been questioned ${ }^{71}$, the functional enrichment of candidate genes under selection has generally lent support to the hypothesis that neural crest genes underlie some of the phenotypic differences between domestic and wild horses ${ }^{72}$ and $\operatorname{dog} s^{73}$. [Au: Edit OK?]

$[\mathrm{H} 3]$ The founder effect. Another widely repeated assumption regarding domestication is that early reproductive isolation was associated with a founder effect, whereby only a subset of the available genetic diversity in the wild population was incorporated into the domesticated population. Lower levels of genetic diversity observed in modern domesticated animal populations have been interpreted to support this claim ${ }^{74-76}$. It is unclear, however, whether this process is a by-product of a domestication bottleneck that took place during the early stages of domestication or a more recent restriction of genetic diversity caused by 19 th and 20th century breeding practices ${ }^{61}$. Interestingly, recent ancient 
plant DNA datasets have demonstrated a decided lack of bottlenecks associated with domestication ${ }^{77}$. This finding is consistent with recent animal studies that have tracked genome-wide patterns of genetic diversity through time and revealed that typically, the majority of genetic diversity was lost during recent centuries and not during the early phases of domestication ${ }^{52,58}$. For example, in horses, individual genome heterozygosity dropped by $\sim 16 \%$ during the past 250 years of breed formation ${ }^{56}$. Similarly, in pigs, runs of homozygosity [G] $(\mathrm{ROH})$ are larger and more frequent in wild animals than in domesticated animals, most likely as a result of overhunting in the wild and restocking with domesticated animals ${ }^{78}$. Modelling of ancient mitochondrial DNA data from cattle suggests that as few as 80 maternal founders precipitated the domestication of cows ${ }^{79}$ but this does not extend to the autosomal genome ${ }^{80}$, suggesting that such domestication bottleneck only affected females [Au: Edit OK?]

\section{[H1] Later stages of domestication}

In recent years, ancient genomic data have dramatically improved our understanding of the early domestication stages, yet many questions remain unresolved. Beyond early stages, these datasets also revolutionized our understanding of later stages of domestication, including processes such as trade and exchanges (Fig. 3), the dynamics of artificial selection [G] , and the process by which people managed animals (that is, animal husbandry) in the past.

\section{[H2] Migration, trade and exchange}

The Bronze Age was a period of substantial cultural and technological innovation that led to dramatic societal changes in agricultural societies ${ }^{81}$. Ancient human genomics studies have revealed that these changes were associated with long-distance migration and concomitant shifts in the patterns of ancestral genomics throughout Eurasia ${ }^{34,82-84}$. Ancient genomic datasets have also demonstrated how this period has affected the ancestry [Au: addition of 'genomics' OK?] of multiple domestic species (Fig. 3). For example, a major shift in horse genomic ancestry took place between 4,100-5,000 thousand years ago, a period that overlaps with the timing of major human population movements, including expansion of the Yamnaya culture [G] and the Sintashta culture $[\mathbf{G}]^{57}$ across Eurasia. Interestingly, the horse population associated with these cultures underwent a substantial demographic expansion during this period. Whether the spread of the Yamnaya or the Sintashta culture in fact triggered or resulted from this expansion requires further investigation.

The Bronze Age was also accompanied by striking shifts in the genomic ancestry of Near Eastern cattle (Bos taurus), which had remained stable during the previous six millennia ${ }^{42}$. This unprecedented genomic turnover reached a magnitude of up to $70 \%$ and was the result of widespread introgression of zebu (Bos indicus) from the Indus valley (Fig.4) ${ }^{42}$. [Au: Please reference this and the previous statement.] This introgression, however, did not affect mitochondrial DNA ancestry, suggesting that the introgression was male-mediated, and therefore promoted by human herders. Interestingly, compared with $B$. taurus, zebus are naturally adapted to dry environmental conditions ${ }^{85}$. The arrival of this novel genetic ancestry may well have sustained cattle husbandry in the Near East during the multi-century droughts that took place during the so-called $4.2 \mathrm{k}$ event ${ }^{42,86}$.

Earlier, Near Eastern goats also witnessed a homogenization of their mitochondrial ancestry ${ }^{43}$. Neolithic populations possessed a strong phylogeographic structure among Anatolian, Levantine and Iranian herds, echoing separations among early farmers and implying the incorporation of a myriad of genetically differentiated bezoar (the wild ancestor of domestic goats) populations during domestication. The correlation between geography and mitochondrial haplogroup eroded during the Chalcolithic period, which witnessed the initial spread of the nowubiquitous haplogroup A throughout the region, and ultimately across the world ${ }^{43}$ (Fig. 3). [Au: Please reference this 
statement.] The mitochondrial ancestry of other species may also have been affected during the Bronze Age. In dogs, for example, the introduction of canine haplogroup A in Europe and the Near East was potentially driven by human migrations from the steppes ${ }^{87}$ (Fig. 3). In pigs, European mitochondrial DNA haplogroups arrive in the Near East during the Late Bronze Age and early Iron Age ${ }^{88}$ (Fig. 3).

Ancient animal genomics has also been used to infer the timeframe over which domesticated lineages were established. For example, material culture has provided evidence for canine harnessing in the Arctic as early as 9,000 years ago ${ }^{12}$. Ancient DNA from these dogs indicates that they belonged to the same genetic lineage as modern Arctic dogs, and that this lineage also gave rise to the earliest native American dogs. This evidence suggests that sledge dogs may have been a key component for the initial peopling of the Americas ${ }^{59}$ (Fig. 3). Within the Americas, however, the dynamics of dog ancestry is complex, as multiple, genetically differentiated lineages of dogs were introduced over the subsequent millennia by Eskimos and European settlers. Strikingly, this introduction of dogs with European ancestry led to the replacement of the dog lineages that were introduced more than 10,000 years ago ${ }^{59}$.

Numerous additional historical processes that have affected domesticated animals over the past 1,500 years have also been uncovered using ancient genomics. For example, the Muslim expansion was accompanied by the spread of Sassanid Persian-related horse ancestry to both Europe and Central Asia, and changed the population structure as well as the genetic makeup of horses after the 7 th-9th century ${ }^{56}$. It is also likely to have contributed to the spread of zebu cattle genetics through the Sahel in Africa ${ }^{145,146}$ (Fig. 4.). [Au: Please reference this statement.] The introduction of pigs from China to the United Kingdom during the Industrial Revolution as part of the breed improvement process ${ }^{89}$ provides an interesting parallel ${ }^{90,91}$. Perhaps the most striking example remains the worldwide spread of numerous modern dog breeds that were established from European stocks during the Victorian era ${ }^{92,93}$.

\section{[H2] Animal husbandry}

The genomes of domesticated animals have been shaped not only by global patterns of migration, trade and exchange, but also by innovations in husbandry practices. Different management practices throughout history have had variable effects on the genomes of domesticated animals, as, generally speaking, genetic diversity decreases as the intensity of management increases. For example, the introduction of studbooks [G] and the breeder's equation [G] after the Industrial Revolution has long been suspected to have resulted in substantial drops in genetic diversity in various domesticated animals. Recent work based on an almost continuous genome time-series of horses confirmed this hypothesis, as the overall diversity of horse genomes decreased substantially only in the past $\sim 250$ years ${ }^{56}$. A similar situation has been reported in dogs, although insufficient ancient genomes have been generated to pinpoint the exact timing of the decline in genetic diversity. Modern dog breeds possess lower genetic diversity than both a 5,000-year old dog genome from Newgrange, Ireland, and modern village dogs, suggesting that modern breeding practices are at least partly responsible for this decline ${ }^{52}$. Pigs, however, do not show any evidence of a decline in genetic diversity over time. This is possibly due to long-term gene flow with European wild boars ${ }^{44,64}$ and the introgression of highly divergent Chinese populations into European pigs as part of the pig improvement phase in the 19th century, which may have masked the diversity loss resulting from recent demographic bottlenecks in modern European breeds ${ }^{94}$. Charting the diversity fluctuations through time in other domesticated species is desirable and is now possible through the generation of time-stamped ancient genomes.

Importantly, reduced levels of genetic diversity may have negative biological consequences, as genetic drift is more prominent in small populations and reduces the efficacy of purifying selection [G]. Consequently, alleles that would otherwise be purged from the population have a greater chance of being maintained at higher frequencies. Thus, even as overall genetic diversity decreases in the population, both the number and proportion of deleterious variants [G] 
in a diploid genome increases, inflating the mutational load [G]. As a result, deleterious alleles have a greater likelihood of being expressed phenotypically. Recent work in horses has provided compelling evidence that the past 250 years of breeding has increased the mutational load ${ }^{56}$, mostly as a result of the development of purebred lines and the decline of draft breeds following the mechanization of agriculture ${ }^{95}$. Similar, or even higher mutational loads may be expected in other species, including dogs and cattle, in which modern breeds are maintained from extremely limited numbers of reproductive animals and which are affected by recurrent genetic defects (for example, in Holstein cattle ${ }^{96}$ ).

In natural conditions, high mutational loads in small populations affect long-term survival by reducing individual fitness. Within human niches, the ramifications of high mutational load for domesticated animals is not as drastic as for wild animals, given human interference and a greater degree of animal care. Additionally, domesticated animals can have extremely high reproductive success (for example, elite bulls) despite having high mutational loads. Therefore, the type of reproductive management developed by breeders can relax selective constraints (relaxed selection [G] ) by partly decoupling mutational loads and fitness, thus leading to an increase in the frequencies of recessive lethal mutations ${ }^{97,98}$.

Breeders also often select related individuals for reproduction, which increases the probability of generating offspring that carry homozygous genotypes. This inbreeding allows deleterious mutations to be phenotypically expressed, even when they are recessive, and can have dramatic biological consequences. Inbreeding can be measured in a single genome by identifying $\mathrm{ROH}$, which can provide a powerful source of information for how breeding practices affect the degree of relatedness in a population. Measuring $\mathrm{ROH}$ requires high-quality genotype calls that are only possible using high-coverage data. Levels of inbreeding have thus far only been estimated in the 5,000-year old dog from Newgrange, the genome of which was sequenced at 25 -fold coverage ${ }^{52}$. The analysis of this genome revealed much smaller and fewer ROH than in modern dog breeds, suggesting that modern breeding practices, and especially modern breed creation and maintenance, are more intense than during the Neolithic Age.

Additional information about past breeding practices can be gleaned by quantifying the number of reproductive males and females in a population. This can be achieved by comparing levels of genetic diversity between sex chromosomes, autosomes and mitochondrial DNA ${ }^{99}$. In cattle, for example, while gene flow from aurochs is evident in the autosomes, it is absent in mitochondrial DNA ${ }^{42}$. This has been interpreted as a management strategy that may have involved allowing insemination of domesticated females by wild bulls ${ }^{42,100}$. In horses, a comparison of the levels of diversity of the Y chromosome and the autosomal chromosomes demonstrated that some cultures allowed fewer males to breed and instead selected specific stallion bloodlines. [ Au: Edit OK? Also, please reference this

statement. Is this Ref. 101?] This male-oriented breeding strategy was not practiced by the Romans, and only became increasingly prominent in the past 1,000 years as a result of the growing influence of Oriental stallions (Arabian, Persian and Turkmen) ${ }^{101}$.

\section{[H2] Artificial selection}

Artificial selection is a hallmark of animal domestication. Characterizing the archaeological context underlying the emergence and spread of key traits is crucial for our overall understanding of domestication. Furthermore, identifying which traits were selected at the onset of domestication is essential for understanding the nature of the transition from wild populations into those that adapted to human niches. Archaeological data can be used to interpret the effects of the transition to domestication by analysing morpho-anatomical traits, such as size, shape and sex ratios. Ancient DNA data have the potential to identify a wide range of phenotypes and potential selection targets (as the relationship between people and animals intensified), as the genetic basis of multiple phenotypic traits has been characterized in modern populations ${ }^{20}$. Ancient sequence data can therefore be used to predict the phenotype of long- 
dead animals, and thus provide insights into the ways in which animals living in close proximity to humans were affected by the shift away from living outside of the human niche. For example, some phenotypes in chickens, such as reduced aggression and faster egg laying, [Au: by faster egg laying, do you mean laying at a younger age or laying more frequently?] have been tracked through time using ancient DNA variation at the thyroid stimulating hormone receptor (TSHR) locus ${ }^{102,103}$ (Fig. 5). These studies demonstrated that a specific TSHR allele (a Gly558Arg missense mutation), [Au: specified the allele. OK?] which is found at high frequencies in modern domestic populations, was not ubiquitous in early chickens ${ }^{102}$. Additional analyses showed that although the frequency of this $T S H R$ allele was $\sim 40 \%$ after chickens arrived in Europe, it was only heavily selected for from $\sim 1,000$ years ago, coincident with a major shift in the intensification of chicken production that is also visible archaeologically across Europe ${ }^{103}$.

Other traits, however, were selected for during early stages of domestication. For example, a single amino acid change in $M C 1 R$, the gene responsible for black coat colour in pigs (Fig. 5), was already present in Anatolian pigs $\sim 8,500$ years ago, suggesting that this trait was selected by early farmers ${ }^{44}$. A similar pattern was reported in both goats

43 and horses ${ }^{104}$, suggesting that coat colouration was one of the earliest targets and markers of domestic animals ${ }^{105}$.

This candidate gene approach is limited, given that the genetic basis of most domestic traits remains unknown. Overlaying functional annotations in the genome with signatures of selection, however, offers an alternative approach for identifying potential past breeding targets. Multiple methods are available to identify selection footprints in the genome. The most common methods make use of the allele frequency differences among pairs of populations, or the extent of linkage disequilibrium within populations ${ }^{106}$. [Au: Edit OK?] Modern allele frequencies are, however, the end product of a temporally-dynamic process that can be retraced using ancient DNA time series. This ancient DNA approach can provide allele frequency trajectories through time (Fig. 5), which represent a powerful source of information to derive both time and intensity of selection ${ }^{103,107,108}$.

The potential of these methods has been best demonstrated in horses and goats, [Au: Edit OK?] for which a range of different selection targets have been identified in a wide range of archaeological contexts. In horses, combined morphometrical and genomic evidence indicates that Scythian horse breeders from Central Asia targeted genes involved in limb formation in their apparent effort to select sturdier morphotypes $\sim 2,500$ years ago ${ }^{72}$. In addition, the locomotory phenotype present in some modern horse breeds, including ambling and speed, was selected only in the past 1,000 years

${ }^{56}$. In goats, selection scans of ancient genomes in Neolithic Iranian and Serbian populations revealed early $(\sim 8,000$ years ago) signatures of selection for genes implicated in coat colour, milking, stature, reproduction and foddering ${ }^{43}$.

\section{[H1] Applications}

\section{[H2] Conservation}

An ancient horse genomics study showed that the direct ancestor of Przewalski's horse, until now considered the only true wild horse, was once a domesticated horse ${ }^{57}$. [Au: Edit OK?] These data sparked controversy concerning the conservation status of this flagship species. Is a horse that became feral thousands of years ago even worth conserving? This question is rooted in the common view that there is an essentialist dichotomy between a wild and a domesticated populations. [Au: Edit OK?] Yet, in the case of Przewalski's horse, should a species discovered in the wild in the 19th century and possessing multiple clear adaptations to its environment now be disregarded as a conservation priority for the sole fact that it interacted with humans some 5,000 years ago? This question has deep implications for conservation biology as a whole. For example, there are many other feral species around the world, some of which have negative impacts on the environment (for example, pigs in Australia, ${ }^{109}$ ) whereas others have neutral or even positive impacts on their ecosystems (for example, sheep in St Kilda ${ }^{110}$ and pigs in the Komodo Islands 
$\left.{ }^{111}\right)$. The question can be extended to multiple other scenarios, [Au: scenarios instead of systems OK?] such as species that have been translocated as wild into non-native environments (for example, pigs in Cyprus ${ }^{112}$ and many other vertebrate species, such as deer or jungle fowl, in Island Southeast Asia ${ }^{113}$ ) or domestic populations that have strong cultural value (for example, rare endangered breeds ${ }^{114,115}$ ) and that provide obvious, considerable services to humans. It is also important to note that an increasing number of archaeological discoveries are leading to a more nuanced view of environments that are considered 'pristine', such as the Amazon basin ${ }^{116-118}$ and Kruger National Park ${ }^{119}$, which in fact have often been extensively modified by humans in the past. By providing the temporal resolution necessary to reconstruct the historical interplay between human activities and the biosphere, the archaeological sciences, including ancient DNA, have the potential to inform conservation priorities beyond the unnecessary, reductive dichotomy between wild and domestic populations.

\section{[H2] Animal health}

Ancient DNA techniques provide access to genetic material not only from the host organism but also from their pathogens. Over the past ten years, ancient pathogen genomics has illuminated the causes and consequences of historical disease epidemics in humans, such as the Justinianic plague $[\mathbf{G}]$ and the Black Death $[\mathbf{G}]^{120}$. Domesticated animals also suffered many epidemics in the past, such as the 18th century European rinderpest epidemic that killed up to $80 \%$ of affected cattle ${ }^{121}$ or, more recently, Marek's disease (20th to 21 st century), which has been reported in over half the countries across the world ${ }^{122}$ and that reached $30-60 \%$ mortality rate in the $1960 \mathrm{~s}^{123}$. In addition, domestication facilitated the emergence of zoonotic diseases with potentially substantial effects on long-term human and animal health. Ancient pathogen genomics is therefore immensely promising in the context of domesticated animals, not only to reveal the history of epidemics in domesticated animals and humans but also to improve our knowledge to fight against infectious diseases in the future. The example of leopard spotted complex, associated with colour night blindness in horses ${ }^{124}$, perfectly illustrates that ancient DNA data may equally be useful to understand the history of genetic disorders and the processes by which they arose (for example, strong artificial selection).

\section{[H1] Perspectives}

Over the past decade, ancient genomics has begun to dramatically shift our understanding of the process of domestication. Numerous studies have provided novel insights into the location, timing and subsequent humanmediated transport of domestic animals, as well as the ways in which domestic animals were selected and managed in the past. By documenting how livestock populations endured both past epidemics and environmental change, ancient genomics can provide invaluable information that can be used to address current and future societal challenges. These insights could prove instrumental in a world in which the farming industry increasingly depends on antibiotics and vaccination, genetic resources for domesticated animal populations are becoming more depleted (for example, $>30 \%$ of domesticated varieties are now endangered ${ }^{125}$ ) and global warming is altering selection pressures.

Although a great deal of progress in understanding animal domestication has been made, a number of key questions remain, especially in species for which ancient genomic data have yet to be generated on a large scale, including cats, sheep, camels, chickens, bees and various micro-organisms, including yeast. [Au: Edit OK?] Even in well-studied species, the available data have often raised more questions than they have answered. This is particularly true for dogs, for which the timing, location and context in which the domestication process was initiated remains uncertain. In addition, whereas new insights have recently been made regarding how humans managed animals in specific cultures, many cultures remain to be investigated. Documenting where and when traits important for 
domestication first emerged, and where and when they were selected will enable the reconstruction of a step by step biological history of domesticated animals.

The genetic architecture of most phenotypic traits is complex and species-specific, as was demonstrated in modern rabbits, in which production traits are highly polygenic ${ }^{76}$. In some cases, however, a quantitative trait can be predicted using only a handful of loci. For example, although height is governed by hundreds of genes in humans ${ }^{126}$, only four loci explain over $80 \%$ of the variance in size in horses ${ }^{127}$. [ Au: specified number of loci. Correct?] This example is the exception, however, and although tackling this genomic complexity is challenging, new methods are being developed to trace polygenic adaptation ${ }^{128}$. These efforts will also benefit from the ongoing efforts of the FAANG consortium, which aims to map regulatory and functional elements onto the genome of economically important livestock ${ }^{129}$. In addition, recent methodological developments in ancient DNA research are providing the potential to genotype variation [Au: genotype instead of type OK?] beyond single nucleotide polymorphisms (SNPs), including copy number variation (CNV), epigenetic markers and faecal and oral microbiomes ${ }^{130}$. Insights gleaned from these approaches will be crucial for our understanding of the recent evolution of complex traits.

The full potential of ancient genomics to generate insights into the pattern and process of domestication has yet to be realized. For example, coat colour, sex determination and genomic relatedness inferred using ancient DNA data can be leveraged to provide crucial information about the ways in which humans and animals interacted (including ritual practices) in past societies ${ }^{72}$. Ancient DNA data can also be used to track hybrid species, including camelid hybrids (for example, tulu) and equine hybrids (such as mules and hinnies ${ }^{131}$ ), which often possessed desirable characteristics that include enhanced immunity and stamina compared with the parental species. Insights such as these can be particularly useful when investigating the military and trade logistics of past societies, and can be supplemented by genetic information extracted from parchment ${ }^{132}$, textiles ${ }^{133}$ and artefacts ${ }^{134}$, to advance our knowledge of past economies.

Over the past few decades, sequencing of ancient DNA has become firmly entrenched within the modern toolkit of bio-archeological research. Combined with data from isotope studies, morphometrics, proteomics and radiocarbon dating, and interpreted within the zooarchaeological context from which the remains were recovered, ancient genomes are generating novel and often surprising insights into both the pattern and process of domestication. These insights are facilitating a new perspective on the relationships that humans have had with animals over at least the past 15,000 years, and how these relationships have become ubiquitous. The next decade will undoubtedly witness a surge in the volume and quality of ancient genomes from an ever wider range of domesticated animal species. The data from these studies will not only enable more accurate reconstruction of the history of genomic shifts associated with the long-term pattern of animal domestication but will also foster a sophisticated understanding of the processes that have led to the emergence of the modern world. 


\section{Acknowledgements}

L.A.F.F. and G.L. were supported either by a European Research Council grant (ERC-2013-396 StG-337574UNDEAD) or Natural Environmental Research Council grants (NE/K005243/1,NE/K003259/1, NE/S00078X/1, NE/S007067/1) or both. L.A.F.F. was also supported by a Wellcome Trust grant (210119/Z/18/Z). L.O. was supported by the European Research Council (ERC) under the European Union's Horizon 2020 research and innovation programme (grant agreement No 681605). D.G.B. was supported by ERC Investigator grant 295729-CodeX.

\section{Author contributions}

The authors contributed equally to all aspects of the article.

\section{Competing interests}

The authors declare no competing interests.

\section{Publisher's note}

Springer Nature remains neutral with regard to jurisdictional claims in published maps and institutional affiliations.

\section{Box 1: Reconstructing population history using ancient genomes}

Over the past decade, many tools have been developed, modified and tested for reconstructing population history using ancient genomes. The first step in analysing ancient genome data generated from a NGS platform is to align the short reads to a reference genome. The most used program is Burrows-Wheeler Aligner (BWA) ${ }^{135}$, which has been extensively tested with ancient DNA ${ }^{136}$. Assembling ancient genomes (instead of aligning to a reference) is often difficult given the highly fragmented nature of ancient DNA molecules, making ancient genomes [Au: do you mean ancient genome sequence data?] fairly difficult to use when no reference genome is available from a closely related species (but see ${ }^{137,138}$ ). Following short-read alignment, the genotype of an ancient sample can be inferred by comparing the sequence of short reads to the reference genome. Single nucleotide polymorphisms (SNPs), which are the result of single point mutations, are the variant type most commonly used to reconstruct population history. [Au: Edit OK?] Other types of 'structural' variation, such as copy number variation (CNV) and insertion or deletion (INDEL), can also be inferred, although working with this type of variation can be challenging due to issues inherent to ancient DNA (for example, small molecules).

The genotype of an ancient genome is then compared to those of other ancient and modern genomes. One popular approach is to compare genotypes at SNPs that have been pre-ascertained in modern population ${ }^{139}$. This method minimizes the incorporation of erroneous SNPs arising from ancient DNA damage (such as deamination) in downstream analyses, although it can also introduce biases ${ }^{35}$. [Au: Edit OK?] Many population genomics tools to infer population structure by comparing genotypes at SNPs in multiple ancient and modern samples exist, some of which have been tailor-made for ancient DNA. Principal components analysis (PCA) is one of the most commonly used tools to infer ancestry ${ }^{140}$ and can accommodate highly degraded and low coverage sequence data by allowing an ancient genome to be 'projected' on to principal component axes. [Au: Edit OK?] Other tools, such as the model-based clustering method ADMIXTURE ${ }^{141}$, can also provide information about population structure and admixture in a set of modern and ancient samples. Additional methods, based on asymmetry in gene trees (D-statistics ${ }^{142}$ ) or allele frequency correlations (F-statistics ${ }^{139}$ ) as well as more explicit graph testing approaches, such as TreeMix ${ }^{143}$ or AdmixtureGraph ${ }^{139}$, are robust tools for testing the existence of gene flow between populations. [Au: Edit OK?] 


\section{Display items}

Figures

[Au: If any figures or parts of figures have been previously published or adapted from previously published figures, we will need to obtain permission from those publishers to adapt or reproduce these figures. Please add this information to the Third Party Rights table and return to us as soon as possible so that we can start obtaining the necessary permissions.]

Figure 1. Increase in the number of published ancient genomes for domesticated animal species. The graph depicts the cumulative number of genomes ( $\geq 1$-fold coverage) or genome-wide data ( $<1$-fold coverage) that have been published each year since 2013, for 5 major domesticated species, cattle, dogs, goats, horses and pigs. The first ancient genome of a domesticated animal, the horse, was published in 2013. Since then, the number of genomes published has increased rapidly, although many species, including chickens and sheep, have not yet been sequenced. [Au: Edit OK?] To date, genomics data for 451 specimens have been reported, including whole genome sequences ( $\geq 1$-fold coverage) for 180 specimens and genome-scale data (<1-fold coverage) for 270 specimens. [Au: Edit OK? Also, please check and correct the number of specimens, as one specimen seems to be missing.] As the cost of sequencing goes down and ancient DNA laboratory protocols become more efficient, this number is expected to keep increasing in the future. [Au: edit OK? presumably the increase will still continue beyond just the next decades.]

Figure 2. Influence of ancient genomics on models of animal domestication. a. The most commonly accepted model of animal domestication prior to generation of ancient genomic data and recent theoretical advances based on zooarchaeology ${ }^{66,144}$. This model involves an initial founder effect that results in a strong demographic bottleneck during early domestication (blue), followed by a dramatic demographic expansion (red), and multiple parallel founder effects during breed formation (green). In this model, mutational load (L) is expected to increase following domestication and then again following breed formation, whereas genetic diversity (D) follows the opposite trend and the strength of artificial selection (A) increases throughout history but is more pronounced during breed formation. $\mathbf{b} \mid \mathrm{A}$ revised model of animal domestication, in which gene flow from one or multiple wild populations have a prominent role and with a limited the initial domestication bottleneck, followed by a dramatic demographic expansion, and multiple parallel founder effects during breed formation. In this model, mutational load is expected to mostly increase following breed formation, whereas genetic diversity decreases at first but then increases again as a result of introgression with wild populations (arrows). The strength of artificial selection also increases throughout history but is more pronounced during breed formation, as in part a. Bars are proportional to the overall levels of mutational load, artificial selection and genetic diversity in the population. The effective population size is represented by the width of the phylogenetic lineages.

Figure 3. Major dispersals of domesticated animals uncovered by ancient genomics. a | Pre-Bronze Age dispersals. Chronologically, the first dispersal shown on this map involves dogs and takes place from Siberia into the Americas, over 10,000 years ago. The second and third dispersals are nearly contemporaneous, involve dogs and pigs, and take place as a result of the spread of farming from the Fertile Crescent into Europe, over 8,000 years ago. The fourth dispersal involves goats originating in Western Anatolia and spreading into the Levant and Iran. [Au: Edit OK?] The last dispersal is hypothetical and involves the potential spread of Botai-related horses $~ 5,000$ years ago from 
Kazakhstan into the surrounding areas, potentially as far as Eastern Europe and China. [Au: specified the geographic details of the dispersal. Please correct as necessary.] b | Post-Bronze Age dispersals. Chronologically, the first dispersal shown on this map involves zebu cattle (Bos indicus) originating in the Indus Valley and spreading to the Near East. The second, hypothetical dispersal involves the potential spread of dogs during the expansion of Steppes cultures into Europe. [Au: The diverging arrow of dog dispersal from southern Europe to North and South America is not mentioned. Is it part of this potential dispersal during expansion of the Steppes cultures? If so, please mention this.]The third dispersal involves dogs and takes place as the result of the expansion of Thule culture (Inuit) into the American Arctic and Greenland 1,000 years ago. The fourth dispersal represents the dispersal of horses showing genetic affinity with Sassanid Persian horses to Europe during the middle ages ( $\sim$ th -9 th century). [Au: specified the geographic details of the dispersal. Please correct as necessary.] The last dispersal represents the dispersal of European dogs into the Americas following the discovery of the "New World" in 1492AD.

Figure 4. Spatiotemporal pattern of admixture between cattle and zebu. [Au: As it is quite difficult to read in the supplied image, please provide a title for the $\mathbf{Y}$ axis of the graph.] The divergence between both the European and African cattle (Bos taurus) genomes and the South Asian zebu (Bos indicus) genome is substantial [Au: substantial instead of profound OK?] and predates domestication. Admixture between these two lineages [Au: two species OK?] has been assessed both temporally and spatially. a $\mid f 4$ ratios estimating zebu ancestry in ancient Near Eastern cattle genomes are plotted and show a fairly sudden influx of zebu genetic ancestry [Au: added 'zebu genetic information'. Please correct as required.] from the Indus Valley region after thousands of years of stasis ${ }^{42}$, possibly driven by the $4.2 \mathrm{k}$ climate event that included multicentury drought across the region. $\mathbf{b}$ | Map showing the current balance of ancestries assessed using multilocus microsatellite variation. Sampled populations are indicated by points and the interpolated gradations vary from 100\% Bos indicus ancestry [Au: added 'ancestry'. Please correct as required.] in their South Asian origin (darkest shading) to purely Bos taurus ancestry (lightest shading) [Au: added 'ancestry'. Please correct as required.]in both Europe and within native breeds of the forest regions of West Africa ${ }^{145,146}$. Zebu introgression was particularly important for establishing the genetic make-up of modern African cattle, and in many regions, such as East Africa and the Sahel, this admixture was likely adaptive, as these zebu breeds perform better than taurine cattle [Au: added 'than B. taurus cattle' to complete comparison. OK?] in warmer, drier conditions.

Fig 5. Frequency of alleles underlying modern phenotypes in key domestic animal species. a The graph depicts the frequency of a derived allele (a Gly558Arg missense mutation ) of TSHR (encoding thyroid-stimulating hormone receptor) in chickens. [Au: Edit OK?] This allele was first found to be under selection in modern chicken populations ${ }^{147}$ and is associated with phenotypes such as longer incubation time (that is, development), [Au: clarified that this refers to development. OK?] fewer fearful behaviours, fewer aggressive behaviours and decreased levels of thyroid hormones ${ }^{148}$. Ancient DNA analysis ${ }^{102,103}$ indicates that the increase in the frequency of this TSHR allele was due to [Au: artificial?] selection, likely taking place during the Middle Ages in Europe. [Au: Edit OK?] b| The graph depicts the frequency of a derived allele (an Asp124Asn missense mutation) of MC1R,encoding encodes melanocortin 1 receptor, in domesticated and wild pigs. This allele results in black coat colour and loss of camouflage coat colour in pigs $^{149}$. Ancient DNA work suggests that this allele was selected very early on during the domestication of pigs, as its frequency was already $\sim 50 \%$ around 8,000 years ago, whereas it is almost absent in the wild $(\sim 2 \%)^{44}$. c| The graph depicts the frequency of a derived allele (a substitution that introduces a premature stop codon; Ser301STOP) in DMRT3 (encoding doublesex and mab3-related transcription factor 3)in horses. This allele is associated with the ability 
to perform gaits in horses (for example, ambling or pacing) ${ }^{150}$. [Au: Edit OK?] Ancient DNA analysis suggests that this allele likely first appeared in Europe during the Middle Ages ${ }^{151}$. As opposed to the example in panel a and $b$, this allele does not become fixed (or nearly fixed in the case of pigs) in the population. This is because only few horse breeds have been selected for the ability to perform gaits and the mutation is therefore still segregating in the worldwide horse population.

\section{Glossary terms}

\section{Neolithic Age [Au: edit to match glossary term in text. OK?]}

Archeological period that began 12,000 years ago in the Near East (later in other parts of the world), following the appearance of farming communities and the domestication of plants and animals. This period marks the latest stage of the 'Stone Age' and ends with the development of metallurgy (Bronze Age).

\section{Bronze Age}

Archeological period that began over 5,000 years ago, in Southern Europe and part of the Near East. This period is associated with the use of bronze and, in some regions, the advent of more urban societies.

\section{Artificial selection}

The process by which humans breed animals to enhance specific characteristics (traits).

\section{Next-generation sequencing}

(NGS). Sequencing technologies that allow researchers to sequence entire genomes (DNA) or transcriptomes (RNA) substantially faster and cheaper than the older technologies. Also known as ultrahigh-throughput sequencing (HTS).

\section{Endogenous DNA}

DNA extracted from the tissue (such as bone or skin) of an organism that is no longer alive, whereas exogenous DNA originates from outside (such as from soil bacteria). The proportion of endogenous DNA molecules can vary considerably depending on the origin and the age of a sample.

\section{Capture techniques}

Also known as target enrichment, these techniques help focus sequencing efforts to a subset of the DNA templates present in DNA libraries, through hybridization to target-specific probes.

\section{[Au: Removed introgressive capture as this term is not present in the text. OK?]}

\section{Neural crest cell}

(NCC). NCCs are temporary cells that differentiate into multiple cell types involved in the formation of the nervous component of bones and cartilages. Research suggests that the behaviour of NCCs may have been modified by domestication, leading to the development of multiple traits that are common across many domesticated animal species (also known as 'domestication syndrome'), including depigmentation, smaller brain, floppy ear and shorter muzzle.

\section{Runs of homozygosity}


(ROH). Regions of the genome that are depleted of heterozygosity, which can arise when a diploid individual inherits two identical stretches of DNA at a specific position of the genome, due to the mating of two closely related parents (such as cousins). The length and the number of $\mathrm{ROH}$ across the genome can provide powerful information to infer levels of inbreeding.

\section{Yamnaya culture}

An early Bronze Age culture from the northern shore of the Black Sea (Pontic steppe).

\section{Sintashta culture}

A Bronze Age culture of the northern Eurasian steppe, which is considered to be an offshoot of the Yamnaya culture.

\section{2k event}

A severe aridification event beginning $~ 4,200$ years ago, which has been hypothesized to have caused the collapse of multiple civilizations across Eurasia.

\section{Studbooks}

Registries that contains the list of animals that belong to the same breed and for which the parents are known.

\section{Breeder's equation}

A mathematical formula that allows breeders to predict the response to selection of a specific heritable trait.

\section{Purifying selection}

Removal of deleterious variants in a population by natural selection. Also known as negative selection.

\section{Deleterious variants}

An allele that has a detrimental effect on the phenotype of an individual.

\section{Mutational load}

The mutational burden in a population or an individual resulting from deleterious variants.

\section{Relaxed selection}

The weakening or removal of a selective pressure, such as when domesticated animals are less subject to selective pressure from predators.

\section{Justinianic plague}

A historical pandemic of Yersinia pestis (541-542 AD) that affected Mediterranean port cities, including Constantinople, and which resulted in the death of 25-50 million people.

\section{Black Death}

A historical pandemic of Yersinia pestis (1346-1353 AD) that resulted in the death of 75-200 million people across Eurasia and which is thought to have had a profound effect on European history. 


\section{Highlighted references}

- Frantz, L.A.F. et al., 2015. Evidence of long-term gene flow and selection during domestication from analyses of Eurasian wild and domestic pig genomes. Nature genetics, 47(10), pp.1141-1148

This paper revealed that extensive gene flow between wild and domestic populations took place during the evolutionary history of pigs and hypothesized that an 'island of domestication' exists in the genome of domestic animals.

- $\quad$ Frantz, L.A.F. et al., 2019. Ancient pigs reveal a near-complete genomic turnover following their introduction to Europe. Proceedings of the National Academy of Sciences of the United States of America, 116(35), pp.17231-17238.

This paper revealed that the Near Eastern ancestry in the genomes of European domestic pigs, which is associated with the first domestic pigs that were introduced into Europe around 8,000 years ago from the Near East, disappeared over 3,000 years ago as a result of interbreeding with local wild boars.

- Frantz, L.A.F. et al., 2016. Genomic and archaeological evidence suggest a dual origin of domestic dogs. Science, 352(6290), pp.1228-1231.

This paper presents the first analysis of an ancient dog genome. Combined with a comprehensive archeological survey, the authors argue for a dual origin of domestic dogs.

- Fages, A. et al., 2019. Tracking Five Millennia of Horse Management with Extensive Ancient Genome Time Series. Cell, 177(6), pp.1419-1435.e31.

This paper represents a milestone in ancient animal genomics, with the sequencing of over 120 ancient horse genomes. The authors draw multiple key conclusions related to the genetic makeup of modern domestic horses and the fitness cost of modern artificial selection.

- Girdland Flink, L. et al., 2014. Establishing the validity of domestication genes using DNA from ancient chickens. Proceedings of the National Academy of Sciences of the United States of America, 111(17), pp.6184-6189.

This study uses ancient DNA to show that mutations that are fixed in modern populations and which were thought to be important during chicken domestication were in fact only the target of recent artificial selection.

- Gaunitz, C. et al., 2018. Ancient genomes revisit the ancestry of domestic and Przewalski's horses. Science, 360(6384), pp.111-114.

This study used ancient horse genomes to show that the Botai horses, which are thought to be the first domestic horses, are not related to modern horses but instead form a lineage that is now almost extinct. The sole representative of this lineage that survived until the present day is modern Przewalski's horses, which were thought to be the last wild horse, but are in fact the descendants of an ancient domesticated population.

- Ní Leathlobhair, M. et al., 2018. The evolutionary history of dogs in the Americas. Science, 361(6397), pp.8185 . 
This study showed that American dogs are the descendant of dogs that dispersed with humans from Siberia into the Americas. Analyses of these genomes revealed that this ancient population of dogs almost completely disappeared after the arrival of Europeans and that the last remnant of this lineage is the genome of the canine transmissible venereal tumour, a contagious cancer clone.

- Orlando, L., Gilbert, M.T.P. \& Willerslev, E., 2015. Reconstructing ancient genomes and epigenomes. Nature reviews Genetics, 16(7), pp.395-408.

A comprehensive review of the techniques for extraction and sequencing of ancient DNA.

- Gamba, C. et al., 2014. Genome flux and stasis in a five millennium transect of European prehistory. Nature communications, 5, p.5257.

This paper identified the petrous temporal bone as the best reservoir of preserved ancient DNA in human remains - a finding that extends to archaeological specimens of domesticated animals and that enables the frequent recovery of whole genome sequences using shotgun sequencing.

- Daly, K.G. et al., 2018. Ancient goat genomes reveal mosaic domestication in the Fertile Crescent. Science, 361(6397), pp.85-88.

The first genome-wide investigation of ancient variation in a Fertile Crescent domesticate, the goat, this study clearly showed the mosaic nature of domestication via Neolithic Iranian, Anatolian and Levantine goat populations and their asymmetric relationships to pre-domestication wild genomes. It also showed 8,000 year old evidence for selection of genes linked to pigmentation and other traits.

- Verdugo, M.P. et al., 2019. Ancient cattle genomics, origins, and rapid turnover in the Fertile Crescent. Science, 365(6449), pp.173-176.

Genome data from ancient Near Eastern cattle and aurochs showed introgression of local aurochs into both early European and Levantine cattle populations. A major shift in genomes occurred $\sim 4,000$ years ago, with widespread introgression of zebu ancestry from the East, possibly linked to multicentury drought.

- Park, S. D. E. et al. Genome sequencing of the extinct Eurasian wild aurochs, Bos primigenius, illuminates the phylogeography and evolution of cattle. Genome Biol. 16, 234 (2015).

The first ancient cattle genome sequenced was that of a Mesolithic British auroch. Although there had been almost no trace found of European auroch mtDNA in modern cattle, these genome data showed that detectable, probably male-mediated, wild introgression had occurred within Europe. [Au: 'Europe' instead of 'that continent' OK?]

- Botigué, L. R. et al. Ancient European dog genomes reveal continuity since the Early Neolithic. Nat. Commun. 8, 16082 (2017).

This paper describes the analysis of two newly sequenced Neolithic dog genomes from Germany. Analyses of these genomes revealed that there was no population replacement in European dogs during the Neolithic Age as 
predicted by Frantz et al. 2016, contradicting the hypothesis that dogs were domesticated more than once.

- Skoglund, P., Ersmark, E., Palkopoulou, E. \& Dalén, L. Ancient wolf genome reveals an early divergence of domestic dog ancestors and admixture into high-latitude breeds. Curr. Biol. 25, 1515-1519 (2015).

The first genome-wide data retrieved from an ancient canid. This paper shows that there was gene flow between arctic dogs and a now extinct population of Siberian wolf.

\section{References}

1. Zeder, M. A. The Domestication of Animals. J. Anthropol. Res. 68, 161-190 (2012).

2. Vigne, J.-D. The origins of animal domestication and husbandry: a major change in the history of humanity and the biosphere. C. R. Biol. 334, 171-181 (2011).

3. Larson, G. et al. Rethinking dog domestication by integrating genetics, archeology, and biogeography. Proc. Natl. Acad. Sci. U. S. A. 109, 8878-8883 (2012).

4. Darwin, C. The Variation of Animals and Plants Under Domestication. (Murray, John, 1868).

5. McHugo, G. P., Dover, M. J. \& MacHugh, D. E. Unlocking the origins and biology of domestic animals using ancient DNA and paleogenomics. BMC Biol. 17, 98 (2019).

6. Conolly, J. et al. Meta-analysis of zooarchaeological data from SW Asia and SE Europe provides insight into the origins and spread of animal husbandry. J. Archaeol. Sci. 38, 538-545 (2011).

7. Vigne, J.-D. Zooarchaeological Aspects of the Neolithic Diet Transition in the Near East and Europe, and Their Putative Relationships with the Neolithic Demographic Transition. in The Neolithic Demographic Transition and its Consequences (eds. Bocquet-Appel, J.-P. \& Bar-Yosef, O.) 179-205 (Springer Netherlands, 2008).

8. Conolly, J. et al. Spatial analysis of faunal remains recovered from PPNA and PPNB sites in SW Asia. in Unpublished presentation at the 11th International Council for Archaeozoology conference, Paris vol. 2328 https://alexandriaarchive.org/bonecommons/items/show/1051 (2010). [Au: Added html link to Bone Commons where this presentation can be obtained.OK?]

9. Ervynck, A., Dobney, K., Hongo, H. \& Meadow, R. Born free? New evidence for the status of 'Sus scrofa’ at Neolithic Çayönü Tepesi (southeastern Anatolia, Turkey). Paléorient 27, 47-73 (2001).

10. Payne, S. Kill-off Patterns in Sheep and Goats: the Mandibles from Aşvan Kale. Anatolian Studies 23, 281-303 (1973)

11. Balasse, M. et al. Wild, domestic and feral? Investigating the status of suids in the Romanian Gumelniţa (5th mil. cal BC) with biogeochemistry and geometric morphometrics. Journal of Anthropological Archaeology 42, 27-36 (2016) 
12. Pitulko, V. V. \& Kasparov, A. K. Archaeological dogs from the Early Holocene Zhokhov site in the Eastern Siberian Arctic. Journal of Archaeological Science: Reports 13, 491-515 (2017).

13. Olsen, S. L. Early horse domestication: weighing the evidence. BAR INTERNATIONAL SERIES 1560, 81 (2006).

14. Larson, G. et al. Worldwide phylogeography of wild boar reveals multiple centers of pig domestication. Science 307, 1618-1621 (2005).

15. Luikart, G. et al. Multiple maternal origins and weak phylogeographic structure in domestic goats. Proc. Natl. Acad. Sci. U. S. A. 98, 5927-5932 (2001).

16. Naderi, S. et al. The goat domestication process inferred from large-scale mitochondrial DNA analysis of wild and domestic individuals. Proc. Natl. Acad. Sci. U. S. A. 105, 17659-17664 (2008).

17. Pedrosa, S. et al. Evidence of three maternal lineages in Near Eastern sheep supporting multiple domestication events. Proc. Biol. Sci. 272, 2211-2217 (2005).

18. Vilà, C. et al. Widespread origins of domestic horse lineages. Science 291, 474-477 (2001).

19. Eriksson, J. et al. Identification of the yellow skin gene reveals a hybrid origin of the domestic chicken. PLoS Genet. 4, e1000010 (2008).

20. Wright, D. Article Commentary: The Genetic Architecture of Domestication in Animals. Bioinform. Biol. Insights 9S4, BBI.S28902 (2015).

21. Shannon, L. M. et al. Genetic structure in village dogs reveals a Central Asian domestication origin. Proc. Natl. Acad. Sci. U. S. A. 112, 13639-13644 (2015).

22. Wang, G.-D. et al. Out of southern East Asia: the natural history of domestic dogs across the world. Cell Res. 26, $21-33$ (2016).

23. Pang, J.-F. et al. mtDNA data indicate a single origin for dogs south of Yangtze River, less than 16,300 years ago, from numerous wolves. Mol. Biol. Evol. 26, 2849-2864 (2009).

24. Higuchi, R., Bowman, B., Freiberger, M., Ryder, O. A. \& Wilson, A. C. DNA sequences from the quagga, an extinct member of the horse family. Nature 312, 282-284 (1984).

25. Pääbo, S. Ancient DNA: extraction, characterization, molecular cloning, and enzymatic amplification. Proc. Natl. Acad. Sci. U. S. A. 86, 1939-1943 (1989).

26. Hagelberg, E. et al. Analysis of ancient bone DNA: techniques and applications. Philos. Trans. R. Soc. Lond. B Biol. Sci. 333, 399-407 (1991).

27. Römpler, H. et al. The Rise and Fall of the Chemoattractant Receptor GPR33. Journal of Biological Chemistry 280, 31068-31075 (2005).

28. Hofreiter, M., Serre, D., Poinar, H. N., Kuch, M. \& Pääbo, S. Ancient DNA. Nat. Rev. Genet. 2, 353-359 (2001). 
29. Gilbert, M. T. P., Bandelt, H.-J., Hofreiter, M. \& Barnes, I. Assessing ancient DNA studies. Trends Ecol. Evol. 20, 541-544 (2005).

30. Goodwin, S., McPherson, J. D. \& McCombie, W. R. Coming of age: ten years of next-generation sequencing technologies. Nat. Rev. Genet. 17, 333-351 (2016).

31. Rasmussen, M. et al. Ancient human genome sequence of an extinct Palaeo-Eskimo. Nature 463, 757-762 (2010).

32. Green, R. E. et al. A draft sequence of the Neandertal genome. Science 328, 710-722 (2010).

33. Orlando, L., Gilbert, M. T. P. \& Willerslev, E. Reconstructing ancient genomes and epigenomes. Nat. Rev. Genet. 16, 395-408 (2015).

34. Haak, W. et al. Massive migration from the steppe was a source for Indo-European languages in Europe. Nature 522, 207-211 (2015).

35. Albrechtsen, A., Nielsen, F. C. \& Nielsen, R. Ascertainment biases in SNP chips affect measures of population divergence. Mol. Biol. Evol. 27, 2534-2547 (2010).

36. Boessenkool, S. et al. Combining bleach and mild predigestion improves ancient DNA recovery from bones. Mol. Ecol. Resour. 17, 742-751 (2017).

37. Gansauge, M.-T. \& Meyer, M. Single-stranded DNA library preparation for the sequencing of ancient or damaged DNA. Nat. Protoc. 8, 737-748 (2013).

38. Gansauge, M.-T. et al. Single-stranded DNA library preparation from highly degraded DNA using T4 DNA ligase. Nucleic Acids Res. 45, e79 (2017).

39. Briggs, A. W. et al. Removal of deaminated cytosines and detection of in vivo methylation in ancient DNA. Nucleic Acids Res. 38, e87 (2010).

40. Rohland, N., Harney, E., Mallick, S., Nordenfelt, S. \& Reich, D. Partial uracil-DNA-glycosylase treatment for screening of ancient DNA. Philos. Trans. R. Soc. Lond. B Biol. Sci. 370, 20130624 (2015).

41. Gamba, C. et al. Genome flux and stasis in a five millennium transect of European prehistory. Nat. Commun. 5, 5257 (2014).

42. Verdugo, M. P. et al. Ancient cattle genomics, origins, and rapid turnover in the Fertile Crescent. Science 365, 173-176 (2019).

43. Daly, K. G. et al. Ancient goat genomes reveal mosaic domestication in the Fertile Crescent. Science 361, 85-88 (2018).

44. Frantz, L. A. F. et al. Ancient pigs reveal a near-complete genomic turnover following their introduction to Europe. Proc. Natl. Acad. Sci. U. S. A. 116, 17231-17238 (2019).

45. Colledge, S., Conolly, J., Dobney, K., Manning, K. \& Shennan, S. Origins and Spread of Domestic Animals in 
Southwest Asia and Europe. (Left Coast Press, 2013).

46. Frantz, L. et al. The Evolution of Suidae. Annu Rev Anim Biosci 4, 61-85 (2016).

47. Helmer, D., Gourichon, L., Monchot, H., Peters, J. \& Segui, M. S. Identifying early domestic cattle from PrePottery Neolithic sites on the Middle Euphrates using sexual dimorphism. in The First Steps of Animal Domestication (eds. -D. Vigne, J., Peters, J. \& Helmer, D.) 86-95 (Oxbow Books, 2005).

48. Hongo, H., Pearson, J., Öksüz, B. \& Ilgezdi, G. The process of ungulate domestication at Cayönü, Southeastern Turkey: a multidisciplinary approach focusing on Bos sp. and Cervus elaphus. Anthropozoologica 44, 63-78 (2009).

49. Perri, A. A wolf in dog's clothing: Initial dog domestication and Pleistocene wolf variation. J. Archaeol. Sci. 68, $1-4$ (2016).

50. Drake, A. G., Coquerelle, M. \& Colombeau, G. 3D morphometric analysis of fossil canid skulls contradicts the suggested domestication of dogs during the late Paleolithic. Sci. Rep. 5, 8299 (2015).

51. Outram, A. K. et al. The earliest horse harnessing and milking. Science 323, 1332-1335 (2009).

52. Frantz, L. A. F. et al. Genomic and archaeological evidence suggest a dual origin of domestic dogs. Science 352, $1228-1231(2016)$.

53. Freedman, A. H. et al. Genome sequencing highlights the dynamic early history of dogs. PLoS Genet. 10, e1004016 (2014)

54. Warmuth, V. et al. Reconstructing the origin and spread of horse domestication in the Eurasian steppe. Proc. Natl. Acad. Sci. U. S. A. 109, 8202-8206 (2012).

55. The Bovine Genome Sequencing and Analysis Consortium et al. The Genome Sequence of Taurine Cattle: A Window to Ruminant Biology and Evolution. Science 324, 522-528 (2009).

56. Fages, A. et al. Tracking Five Millennia of Horse Management with Extensive Ancient Genome Time Series. Cell 177, 1419-1435.e31 (2019).

57. Gaunitz, C. et al. Ancient genomes revisit the ancestry of domestic and Przewalski's horses. Science 360, 111-114 (2018).

58. Botigué, L. R. et al. Ancient European dog genomes reveal continuity since the Early Neolithic. Nat. Commun. 8, 16082 (2017).

59. Ní Leathlobhair, M. et al. The evolutionary history of dogs in the Americas. Science 361, 81-85 (2018).

60. Leonard, J. A. et al. Ancient DNA evidence for Old World origin of New World dogs. Science 298, 1613-1616 (2002).

61. Frantz, L. A. F. \& Larson, G. A genetic perspective on the domestication continuum. in Hybrid Communities (eds. 
Stépanoff, C. \& Vigne, J.-D.) 23-37 (Routledge, 2018).

62. Larson, G. \& Burger, J. A population genetics view of animal domestication. Trends Genet. 29, 197-205 (2013).

63. Park, S. D. E. et al. Genome sequencing of the extinct Eurasian wild aurochs, Bos primigenius, illuminates the phylogeography and evolution of cattle. Genome Biol. 16, 234 (2015).

64. Frantz, L. A. F. et al. Evidence of long-term gene flow and selection during domestication from analyses of Eurasian wild and domestic pig genomes. Nat. Genet. 47, 1141-1148 (2015).

65. Skoglund, P., Ersmark, E., Palkopoulou, E. \& Dalén, L. Ancient wolf genome reveals an early divergence of domestic dog ancestors and admixture into high-latitude breeds. Curr. Biol. 25, 1515-1519 (2015).

66. Marshall, F. B., Dobney, K., Denham, T. \& Capriles, J. M. Evaluating the roles of directed breeding and gene flow in animal domestication. Proc. Natl. Acad. Sci. U. S. A. 111, 6153-6158 (2014).

67. Schubert, M. et al. Prehistoric genomes reveal the genetic foundation and cost of horse domestication. Proc. Natl. Acad. Sci. U. S. A. 111, E5661-9 (2014).

68. Turner, T. L., Hahn, M. W. \& Nuzhdin, S. V. Genomic islands of speciation in Anopheles gambiae. PLoS Biol. 3, e285 (2005)

69. Briggs, W. H., McMullen, M. D., Gaut, B. S. \& Doebley, J. Linkage Mapping of Domestication Loci in a Large Maize-Teosinte Backcross Resource. Genetics 177, 1915-1928 (2007).

70. Trut, L. Early Canid Domestication: The Farm-Fox Experiment Foxes bred for tamability in a 40-year experiment exhibit remarkable transformations that suggest an interplay between behavioral genetics and development. Am. Sci. 87, 160-169 (1999).

71. Lord, K. A., Larson, G., Coppinger, R. P. \& Karlsson, E. K. The History of Farm Foxes Undermines the Animal Domestication Syndrome. Trends Ecol. Evol. 35, 125-136 (2020).

72. Librado, P. et al. Ancient genomic changes associated with domestication of the horse. Science 356, 442-445 (2017).

73. Pendleton, A. L. et al. Comparison of village dog and wolf genomes highlights the role of the neural crest in dog domestication. BMC Biology 16, 64 (2018).

74. Marsden, C. D. et al. Bottlenecks and selective sweeps during domestication have increased deleterious genetic variation in dogs. Proc. Natl. Acad. Sci. U. S. A. 113, 152-157 (2016).

75. MacLeod, I. M., Larkin, D. M., Lewin, H. A., Hayes, B. J. \& Goddard, M. E. Inferring demography from runs of homozygosity in whole-genome sequence, with correction for sequence errors. Mol. Biol. Evol. 30, 2209-2223 (2013).

76. Carneiro, M. et al. Rabbit genome analysis reveals a polygenic basis for phenotypic change during domestication. 
Science 345, 1074-1079 (2014).

77. Allaby, R. G., Ware, R. L. \& Kistler, L. A re-evaluation of the domestication bottleneck from archaeogenomic evidence. Evol. Appl. 12, 29-37 (2019).

78. Bosse, M. et al. Regions of homozygosity in the porcine genome: consequence of demography and the recombination landscape. PLoS Genet. 8, e1003100 (2012).

79. Bollongino, R. et al. Modern taurine cattle descended from small number of near-eastern founders. Mol. Biol. Evol. 29, 2101-2104 (2012).

80. Murray, C., Huerta-Sanchez, E., Casey, F. \& Bradley, D. G. Cattle demographic history modelled from autosomal sequence variation. Philos. Trans. R. Soc. Lond. B Biol. Sci. 365, 2531-2539 (2010).

81. Kristiansen, K. The Rise of Bronze Age Society: Travels, Transmissions and Transformations. (Cambridge University Press, 2005).

82. Allentoft, M. E. et al. Population genomics of Bronze Age Eurasia. Nature 522, 167-172 (2015).

83. Damgaard, P. de B. et al. 137 ancient human genomes from across the Eurasian steppes. Nature 557, 369-374 (2018).

84. Jeong, C. et al. Bronze Age population dynamics and the rise of dairy pastoralism on the eastern Eurasian steppe. Proc. Natl. Acad. Sci. U. S. A. 115, E11248-E11255 (2018).

85. Hansen, P. J. Physiological and cellular adaptations of zebu cattle to thermal stress. Anim. Reprod. Sci. 82-83, 349-360 (2004).

86. Matthews, R. Zebu: harbingers of doom in Bronze Age western Asia? Antiquity 76, 438-446 (2002).

87. Ollivier, M. et al. Dogs accompanied humans during the Neolithic expansion into Europe. Biol. Lett. 14, pii: 20180286 (2018).

88. Ottoni, C. et al. Pig domestication and human-mediated dispersal in western Eurasia revealed through ancient DNA and geometric morphometrics. Mol. Biol. Evol. 30, 824-832 (2013).

89. White, S. From Globalized Pig Breeds to Capitalist Pigs: A Study in Animal Cultures and Evolutionary History. Environ. Hist. Durh. N. C. 16, 94-120 (2011).

90. Bosse, M. et al. Genomic analysis reveals selection for Asian genes in European pigs following human-mediated introgression. Nat. Commun. 5, 4392 (2014).

91. Bosse, M. et al. Artificial selection on introduced Asian haplotypes shaped the genetic architecture in European commercial pigs. Proc. Biol. Sci. 282, 20152019 (2015).

92. Shearin, A. L. \& Ostrander, E. A. Canine morphology: hunting for genes and tracking mutations. PLoS Biol. 8, e1000310 (2010). 
93. Boyko, A. R. The domestic dog: man's best friend in the genomic era. Genome Biol. 12, 216 (2011).

94. Bosse, M. et al. Untangling the hybrid nature of modern pig genomes: a mosaic derived from biogeographically distinct and highly divergent Sus scrofa populations. Mol. Ecol. 23, 4089-4102 (2014).

95. Orlando, L. \& Librado, P. Origin and Evolution of Deleterious Mutations in Horses. Genes 10, pii: E649 (2019).

96. Oltenacu, P. A. \& Algers, B. Selection for increased production and the welfare of dairy cows: are new breeding goals needed? Ambio 34, 311-315 (2005).

97. Charlier, C. et al. NGS-based reverse genetic screen for common embryonic lethal mutations compromising fertility in livestock. Genome Res. 26, 1333-1341 (2016).

98. Derks, M. F. L. et al. Loss of function mutations in essential genes cause embryonic lethality in pigs. PLoS Genet. 15, e1008055 (2019).

99. Ellegren, H. The different levels of genetic diversity in sex chromosomes and autosomes. Trends Genet. 25, 278284 (2009).

100. Peters, J., Arbuckle, B. S. \& Pöllath, N. Subsistence and beyond: animals in Neolithic Anatolia. in The Neolithic in Turkey, VOL. 6 (eds. Özdogan, M., Baflgelen, N. \& Kuniholm, P.) 1-65 (Archaeology and Art Publications, 2012).

101. Wallner, B. et al. Y Chromosome Uncovers the Recent Oriental Origin of Modern Stallions. Curr. Biol. 27, 20292035.e5 (2017).

102. Girdland Flink, L. et al. Establishing the validity of domestication genes using DNA from ancient chickens. Proc. Natl. Acad. Sci. U. S. A. 111, 6184-6189 (2014).

103. Loog, L. et al. Inferring Allele Frequency Trajectories from Ancient DNA Indicates That Selection on a Chicken Gene Coincided with Changes in Medieval Husbandry Practices. Mol. Biol. Evol. 34, 1981-1990 (2017).

104. Ludwig, A. et al. Coat color variation at the beginning of horse domestication. Science 324, 485 (2009).

105. Linderholm, A. \& Larson, G. The role of humans in facilitating and sustaining coat colour variation in domestic animals. Semin. Cell Dev. Biol. 24, 587-593 (2013).

106. Pavlidis, P., Jensen, J. D. \& Stephan, W. Searching for footprints of positive selection in whole-genome SNP data from nonequilibrium populations. Genetics 185, 907-922 (2010).

107. Schraiber, J. G., Evans, S. N. \& Slatkin, M. Bayesian Inference of Natural Selection from Allele Frequency Time Series. Genetics 203, 493-511 (2016).

108. Malaspinas, A.-S. Methods to characterize selective sweeps using time serial samples: an ancient DNA perspective. Mol. Ecol. 25, 24-41 (2016).

109. Barrios-Garcia, M. N. \& Ballari, S. A. Impact of wild boar (Sus scrofa) in its introduced and native range: a 
review. Biol. Invasions 14, 2283-2300 (2012).

110. Boyd, J. M., Doney, J. M., Gunn, R. G. \& Jewell, P. A. The Soay sheep of the island of Hirta, St. Kilda. A study of a feral population. in Proceedings of the Zoological Society of London vol. 142 129-164 (Wiley Online Library, 1964).

111. Ariefiandy, A. et al. Temporal and spatial dynamics of insular Rusa deer and wild pig populations in Komodo National Park. J. Mammal. 97, 1652-1662 (2016).

112. Vigne, J.-D. et al. Pre-Neolithic wild boar management and introduction to Cyprus more than 11,400 years ago. Proc. Natl. Acad. Sci. U. S. A. 106, 16135-16138 (2009).

113. Heinsohn, T. Animal translocation: long-term human influences on the vertebrate zoogeography of Australasia (natural dispersal versus ethnophoresy). Aust. Zool. 32, 351-376 (2003).

114. Taberlet, P. et al. Are cattle, sheep, and goats endangered species? Mol. Ecol. 17, 275-284 (2008).

115. Taberlet, P., Coissac, E., Pansu, J. \& Pompanon, F. Conservation genetics of cattle, sheep, and goats. C. R. Biol. 334, 247-254 (2011).

116. Heckenberger, M. J., Russell, J. C., Toney, J. R. \& Schmidt, M. J. The legacy of cultural landscapes in the Brazilian Amazon: implications for biodiversity. Philos. Trans. R. Soc. Lond. B Biol. Sci. 362, 197-208 (2007).

117. Ellis, E. C. et al. Used planet: a global history. Proc. Natl. Acad. Sci. U. S. A. 110, 7978-7985 (2013).

118. Piperno, D. R., McMichael, C. \& Bush, M. B. Amazonia and the Anthropocene: What was the spatial extent and intensity of human landscape modification in the Amazon Basin at the end of prehistory? Holocene 25, 1588-1597 (2015).

119. Plug, I. Aspects of Life in the Kruger National Park during the Early Iron Age. Goodwin Series 6, 62-68 (1989).

120. Spyrou, M. A., Bos, K. I., Herbig, A. \& Krause, J. Ancient pathogen genomics as an emerging tool for infectious disease research. Nature Reviews Genetics 20, 323-340 (2019).

121. Roman-Binois, A. L'archéologie des épizooties: mise en évidence et diagnostic des crises de mortalité chez les animaux d'élevage, du Néolithique à Pasteur. (Université Panthéon-Sorbonne-Paris I, 2017).

122. Boodhoo, N., Gurung, A., Sharif, S. \& Behboudi, S. Marek's disease in chickens: a review with focus on immunology. Vet. Res. 47, 119 (2016).

123. Witter, R. L. The changing landscape of Marek’s disease. Avian Pathol. 27, S46-S53 (1998).

124. Bellone, R. R. et al. Evidence for a retroviral insertion in TRPM1 as the cause of congenital stationary night blindness and leopard complex spotting in the horse. PLoS One 8, e78280 (2013).

125. FAO. Domestic Animal Diversity Information System. DAD-IS http://dad.fao.org/ (2017).

126. Wood, A. R. et al. Defining the role of common variation in the genomic and biological architecture of adult 
human height. Nat. Genet. 46, 1173-1186 (2014).

127. Makvandi-Nejad, S. et al. Four loci explain 83\% of size variation in the horse. PLoS One 7, e39929 (2012).

128. Racimo, F., Sankararaman, S., Nielsen, R. \& Huerta-Sánchez, E. Evidence for archaic adaptive introgression in humans. Nat. Rev. Genet. 16, 359-371 (2015).

129. Andersson, L. et al. Coordinated international action to accelerate genome-to-phenome with FAANG, the Functional Annotation of Animal Genomes project. Genome Biol. 16, 57 (2015).

130. Warinner, C. et al. Pathogens and host immunity in the ancient human oral cavity. Nat. Genet. 46, 336-344 (2014).

131. Schubert, M. et al. Zonkey: A simple, accurate and sensitive pipeline to genetically identify equine F1-hybrids in archaeological assemblages. J. Archaeol. Sci. 78, 147-157 (2017).

132. Teasdale, M. D. et al. Paging through history: parchment as a reservoir of ancient DNA for next generation sequencing. Philos. Trans. R. Soc. Lond. B Biol. Sci. 370, 20130379 (2015).

133. O’Sullivan, N. J. et al. A whole mitochondria analysis of the Tyrolean Iceman's leather provides insights into the animal sources of Copper Age clothing. Sci. Rep. 6, 31279 (2016).

134. Bro-Jørgensen, M. H. et al. Ancient DNA analysis of Scandinavian medieval drinking horns and the horn of the last aurochs bull. J. Archaeol. Sci. 99, 47-54 (2018).

135. Li, H. \& Durbin, R. Fast and accurate short read alignment with Burrows-Wheeler transform. Bioinformatics 25, 1754-1760 (2009).

136. Schubert, M. et al. Improving ancient DNA read mapping against modern reference genomes. BMC Genomics 13, 178 (2012).

137. Rajaraman, A., Tannier, E. \& Chauve, C. FPSAC: fast phylogenetic scaffolding of ancient contigs. Bioinformatics 29, 2987-2994 (2013).

138. Seitz, A. \& Nieselt, K. Improving ancient DNA genome assembly. PeerJ 5, e3126 (2017).

139. Patterson, N. et al. Ancient admixture in human history. Genetics 192, 1065-1093 (2012).

140. Patterson, N., Price, A. L. \& Reich, D. Population structure and eigenanalysis. PLoS Genet. 2, e190 (2006).

141. Alexander, D. H., Novembre, J. \& Lange, K. Fast model-based estimation of ancestry in unrelated individuals. Genome Res. 19, 1655-1664 (2009).

142. Durand, E. Y., Patterson, N., Reich, D. \& Slatkin, M. Testing for ancient admixture between closely related populations. Mol. Biol. Evol. 28, 2239-2252 (2011).

143. Pickrell, J. K. \& Pritchard, J. K. Inference of population splits and mixtures from genome-wide allele frequency data. PLoS Genet. 8, e1002967 (2012).

144. Zeder, M. A. Pathways to animal domestication. in Harlan II: Biodiversity in Agriculture: Domestication, 
Evolution and Sustainability (eds. Damania, A. \& Gepts, P.) 227-229 (Univ California Press, 2011).

145. Hanotte, O. et al. African pastoralism: genetic imprints of origins and migrations. Science 296, 336-339 (2002).

146. Freeman, A. R., Bradley, D. G., Nagda, S., Gibson, J. P. \& Hanotte, O. Combination of multiple microsatellite data sets to investigate genetic diversity and admixture of domestic cattle. Anim. Genet. 37, 1-9 (2006).

147. Rubin, C.-J. et al. Whole-genome resequencing reveals loci under selection during chicken domestication. Nature 464, 587-591 (2010).

148. Karlsson, A.-C. et al. The Effect of a Mutation in the Thyroid Stimulating Hormone Receptor (TSHR) on Development, Behaviour and TH Levels in Domesticated Chickens. PLoS One 10, e0129040 (2015).

149. Fang, M., Larson, G., Ribeiro, H. S., Li, N. \& Andersson, L. Contrasting mode of evolution at a coat color locus in wild and domestic pigs. PLoS Genet. 5, e1000341 (2009).

150. Andersson, L. S. et al. Mutations in DMRT3 affect locomotion in horses and spinal circuit function in mice. Nature 488, 642-646 (2012).

151. Wutke, S. et al. The origin of ambling horses. Curr. Biol. 26, R697-R699 (2016). 